\title{
Neurexins Are Differentially Expressed in the Embryonic Nervous System of Mice
}

\author{
Andreas W. Püschel and Heinrich Betz \\ Abteilung Neurochemie, Max-Planck-Institut für Hirnforschung, D-60528 Frankfurt/Main, Germany
}

\begin{abstract}
Expression of the major isoforms of three neurexin genes was analyzed in the developing embryonic nervous system of mice by Northern blot and in situ hybridization. Transcripts of all three genes were detected as early as embryonic day 10 (E10) and increased with maturation of the nervous system. RNAs of the major neurexin isoforms ( $\alpha$ and B) were found throughout the central nervous system exclusively in postmitotic neurons and at least $1 \mathrm{~d}$ before synapses are formed. In contrast, in the PNS the $\alpha$ - and $\beta$-isoforms displayed differential expression patterns. Neurexin III mRNA showed a more restricted regional expression than neurexin I and II transcripts. These expression profiles are consistent with the hypothesis that the neurexins have a function in early neuronal differentiation and axogenesis.
\end{abstract}

[Key words: development, dorsal root ganglion, mouse, neurexin, spinal cord, sympathetic ganglion]

The neurexins are encoded by a small family of three highly related genes (Ushkaryov et al., 1992; Ushkaryov and Südhof, 1993). Originally the neurexins were isolated as major components of the $\alpha$-latrotoxin receptor (Meldolesi, 1982; Ushkaryov et al., 1992; Petrenko, 1993). This toxin induces a massive $\mathrm{Ca}^{2+}$ independent release of $\mathrm{ACh}$ when applied to neuromuscular junctions (Frontali ct al., 1976; Nicholls ct al., 1982; Deri ct al., 1993), and neurexins therefore may be involved in the regulated vesicular release of neurotransmitters at synaptic terminals. Sequence analysis suggests that the neurexins are proteins with a single transmembrane domain. Each gene generates two major RNA isoforms (Ushkaryov et al., 1992), which in the case of neurexins I and II encode proteins with large ( $\alpha$ form) or small ( $\beta$ form) extracellular domains (Fig. 1). The extracellular domain of the $\alpha$-form contains three internal repeats of 406 amino acids with homologies to agrin, laminin $\mathrm{A}$, and EGF-repeats. The shorter $\beta$-form contains only the $\mathrm{C}$-terminal half of the third neurexin-repeat. For neurexin III only sequences coding for a large $\alpha$-variant have been reported (Ushkaryov et al., 1992). Alternative splicing of the neurexin III transcript generates membrane-bound and potentially secreted isoforms (Ushkaryov et al., 1992). In addition differential splicing of exons encoding segments of the extracellular domain generates a vast number of

\footnotetext{
Received July 15, 1994; revised Oct. 18, 1994; accepted Oct. 20, 1994.
}

We thank Birgit Pilz for expert technical assistance, and M. Ehms-Sommer for help with photography. This work was supported by the Deutsche Forschungsgemeinschaft (Leibniz-Programm and SГB 269).

Correspondence should be addressed to H. Betz, Abteilung Neurochemie, Max-Planck-Institut für Hirnforschung, Deutschordenstrasse 46, D-60528 Frankfurt/Main, Germany.

Copyright $\mathcal{C} 1995$ Society for Neuroscience $\quad 0270-6474 / 95 / 152849-08 \$ 05.00 / 0$ neurexin isoforms that differ in several short amino acid stretches.

The intracellular domain of neurexin I $\alpha$ was shown to bind in vitro to synaptotagmin (Petrenko et al., 1991; Hata et al., 1993; Perin, 1994), a major integral membrane protein of synaptic vesicles. Moreover, after purification on an $\alpha$-latrotoxin column neurexin I $\alpha$ was found to be associated with several proteins thought to be essential for the fusion of synaptic vesicles with the plasma membrane (O'Connor et al., 1993). It was therefore argued that neurexins are an important component of the machinery mediating the regulated release of neurotransmitters. So far, however, direct binding of $\alpha$-latrotoxin to native or recombinant neurexins has not been demonstrated, and physiological evidence for a function of neurexins in the regulated release of neurotransmitters is lacking. The sequence and structural homology of the neurexins to extracellular matrix molecules as well as their high polymorphism generated by alternative splicing suggests that neurexins might function as cell recognition molecules of the nerve terminal (Ushkaryov et al., 1992).

To validate this hypothesis we examined whether neurexins are expressed during the embryonic development of the murine nervous system. Here we report on the spatial and temporal expression profiles of the major isoforms of neurexin I, II, and III. Transcripts of all three genes were found in the embryonic CNS and PNS at early embryonic stages when most neurons are born. We detected a new neurexin I transcript which is more abundant than the previously reported $\alpha$ and $\beta$ mRNAs. Whereas all isoforms of neurexin I and II are expressed in the spinal cord, they show a differential expression in dorsal root ganglia (DRG) and sympathetic ganglia. Neurexin III is expressed at a lower level in a smaller number of cells in the CNS and is absent from the PNS. As has been observed for the transcripts of other genes encoding proteins involved in vesicular release, transcription of the neurexin genes precedes synaptogenesis. Our results are consistent with the idea that neurexins could be involved in early neuronal differentiation and axogenesis.

\section{Materials and Methods}

Animals. NMRI outbred mice were purchased from the Zentralinstitut für Versuchstierzucht (Hannover, Germany). The day of detection of the vaginal plug was designated embryonic day zero (E0). Embryos between embryonic day 10 and E15 were fixed overnight in $4 \%(\mathrm{w} / \mathrm{v})$ formaldehyde in phosphate-buffered saline, dehydrated, embedded in paraffin, and processed for in situ hybridization as described previously (Püschel et al., 1992).

Recombinant DNA. To generate probes specific for murine neurexin transcripts, fragments from different parts of the mRNAs were amplified from cDNA by the polymerase chain reaction (PCR). Total RNA from adult brain and $\mathrm{E} 15$ embryos was prepared by standard procedures. The tissue was lysed in $4 \mathrm{M}$ guanidinium thiocyanate and purified by cen- 
Neurexin $\mid \alpha$
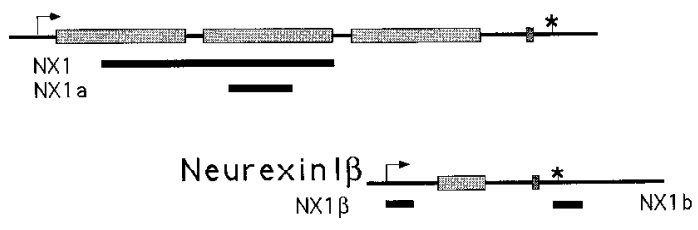

Neurexinll $\alpha$
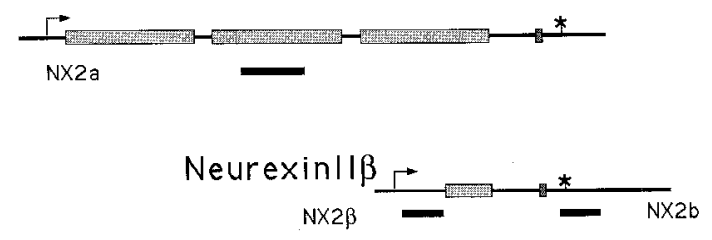

Neurexinll

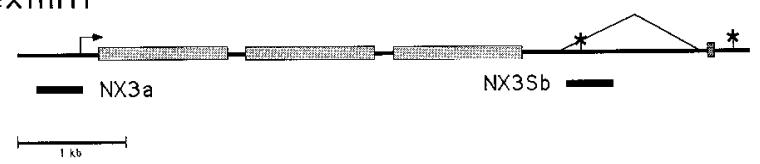

Figure 1. Schematic representation of the neurexin mRNAs (neurexin I, II, and III) and the hybridization probes (NX1, NX2, and NX3) used. A schematic representation of transcripts corresponding to the $\alpha-, \beta-$, and secreted neurexin isoforms is shown together with the location of the different probes used (indicated by solid bars). Lightly stippled box$e s$ correspond to the internal repeats in the extracellular domain, heavily stippled boxes to putative transmembrane domains, arrows to start codons, and stars to stop codons, respectively. In the neurexin III transcript an alternative splice site is indicated, which gives rise to the membrane-bound variant. Use of a downstream splice site and translation of the intronic sequences creates a potentially secreted form. Isoform-specific probes for neurexins I, II, and III were generated using the primers listed in Table 1. trifugation through a $5.7 \mathrm{M}$ cesium chloride cushion as described previously (Puischel et al., 1990). PolyA ${ }^{+}$RNA was prepared using the polyATract system (Promega). cDNA was generated form $1 \mu \mathrm{g}$ of polyA+ RNA in a final volume of $20 \mu \mathrm{l}$ using a cDNA synthesis kit (Boehringer Mannheim) according to the manufacturer's specifications. PCR was performed with $1 \mu$ laliquots of a cDNA synthesis using 100 pmol of each primer (Table 1) and 5 U Taq polymerase (GIBCO-Bethesda Research Labs) according to the manufacturer's specifications at a final $\mathrm{MgCl}_{2}$ concentration of $3 \mathrm{~mm}$.

To avoid cross-hybridization of the probes, primer sequences were chosen from untranslated sequences whenever possible. Attempts to isolate by PCR probes specific for the $5^{\prime}$ nontranslated sequences of the neurexin I and II mRNA were unsuccessful. We therefore used probes corresponding to the coding part of both transcripts (NX1a, NX2a; see Fig. 1) which were specific under the conditions used as they gave distinct signals both in Northern blot and in situ hybridizations. Probes derived from $3^{\prime}$ nontranslated sequences (NX1b, NX2b) should detect both $\alpha$ and $\beta$ forms of neurexins I and II. The probes derived from the $5^{\prime}$ nontranslated part of the $\beta$ forms (NX1 $\beta$ and NX2 $\beta$ ) are specific for neurexins $I \beta$ and $I \beta$, respectively. Probes NX3a, NX3Sa, and NX3Sb were designed to recognize the transcripts encoding the membranebound and one secreted form of neurexin III, respectively, whereas the NX3a probe detects all published neurexin III isoforms. Primers for probe NX3Sa, however, gave a product only when using rat brain CDNA.

PCR fragments were generated by 30 cycles of denaturation $(1 \mathrm{~min}$, $\left.94^{\circ} \mathrm{C}\right)$, annealing $\left(1.5 \mathrm{~min}, 60^{\circ} \mathrm{C}\right)$ and extension $\left(1.5 \mathrm{~min}, 72^{\circ} \mathrm{C}\right)$, digested with EcoRI and BamHI (New England Biolabs), purified and subcloned into Bluescript (Stratagene). The identity of the plasmids was confirmed by partial sequencing (Pharmacia 17 sequencing kit).

Northern hybridization. Two micrograms of polyA ${ }^{+}$mRNA were separated on formaldehyde gels and blotted onto positively charged nylon membranes (Boehringer Mannheim). Cloned PCR fragments and a $1.9 \mathrm{~kb}$ fragment (probe NX1) derived from the pCMV-neurexin I plasmid (generously provided by T. Südhof; Ushkaryov et al., 1992) were randomly labeled with ${ }^{32} \mathrm{P}$ (Pharmacia random-labeling kit). Hybridizations was performed in $50 \%(\mathrm{v} / \mathrm{v})$ formamide (Fluka), $5 \times$ salinesodium citrate (SSC), $5 \times$ Denhardt's solution, $25 \mathrm{~mm}$ sodium phosphate buffer ( $\mathrm{pH} 6.8$ ), $5 \mathrm{~mm}$ EDTA, $0.1 \%(\mathrm{w} / \mathrm{v})$ sodium dodecyl sulfate (SDS), and $100 \mu \mathrm{g} / \mathrm{ml}$ calf thymus DNA (Sigma) at $60^{\circ} \mathrm{C}$ overnight. The filters were washed twice at room temperature for $5 \mathrm{~min}$, twice at

Table 1. PCR primers used for generating neurexin probes

\begin{tabular}{|c|c|c|c|}
\hline Probe & Primers & Positions $^{a}$ & $\begin{array}{l}\text { Fragment } \\
\text { length (bp) }\end{array}$ \\
\hline \multirow[t]{2}{*}{ NX1a } & GAGGATCCGAA/GTGGTGT/CCAC/TGTGGATT & $2578-2596$ & 502 \\
\hline & GAGAATTCTCC/TTCTGCC/TTCCGTG/ATGCAT & $3061-3080$ & \\
\hline \multirow[t]{2}{*}{ NX1b } & GGGAATTCGAGAAGCAGCCCAGCAGTGC & $5312-5331$ & 200 \\
\hline & GAGGATCCCCTCCTGATCGCATTCCCTG & $5470-5490$ & \\
\hline \multirow[t]{2}{*}{ NX1 $1 \beta$} & GAGGATCCCGCCATGTACCAGAGGATG & $120-139$ & 268 \\
\hline & GGGAATTCGATATACGTCGTCCCAGCG & $387-368$ & \\
\hline \multirow[t]{2}{*}{ NX2a } & GAGGATCCGAA/GTGGTGT/CCAC/TGTGGATT & 19751994 & 505 \\
\hline & GAGAATTCTCC/TTCTGCC/TTCCGTG/ATGCAT & $2480-2461$ & \\
\hline \multirow[t]{2}{*}{$\mathrm{NX} 2 \mathrm{~b}$} & GGGAATTCCCCAAGACGCCCAGCAAGGC & $5313-5321$ & 310 \\
\hline & GAGGATCCCTGACAGGCGCAGAGCGGAG & $5614-5594$ & \\
\hline \multirow[t]{2}{*}{$N X 2 \beta$} & AAGAATTCCCGCCGCTGCCGCTTCTGC & $535-554$ & 186 \\
\hline & GGGGATCCGATGTATGTGGTCCCAGCG & $720-701$ & \\
\hline \multirow[t]{2}{*}{ NX3a } & AGAGGATCCTGGGCTACTTCTCCTTG & $409-426$ & 370 \\
\hline & GGGAATTCGGAGGGTAAAGCTCATGTTG & $778-758$ & \\
\hline \multirow[t]{2}{*}{ NX3Sa } & GGGAATTCGTGCCGCCCTTACATGGAC & $4908-4926$ & 670 \\
\hline & GAGGATCCCTCATCAACAAATTGCCCGC & $5578-5559$ & \\
\hline \multirow[t]{2}{*}{$\mathrm{NX} 3 \mathrm{Sb}$} & GGGAATTCGTGCCGCCCTTACATGGAC & $4908-4926$ & 374 \\
\hline & GCGGATCCCTTTGGAGGGACTTAGGATG & $5282-5263$ & \\
\hline
\end{tabular}

a Positions of primers taken from published cDNA sequences (Ushkaryov et al., 1992; Ushkaryov and Südhof, 1993). 


\section{$\frac{N X 1}{N A} \frac{N X 1 a}{N A} \frac{N X 1 b}{N A} \frac{N \times 1 \beta}{N A E 12 E 15}$}

A
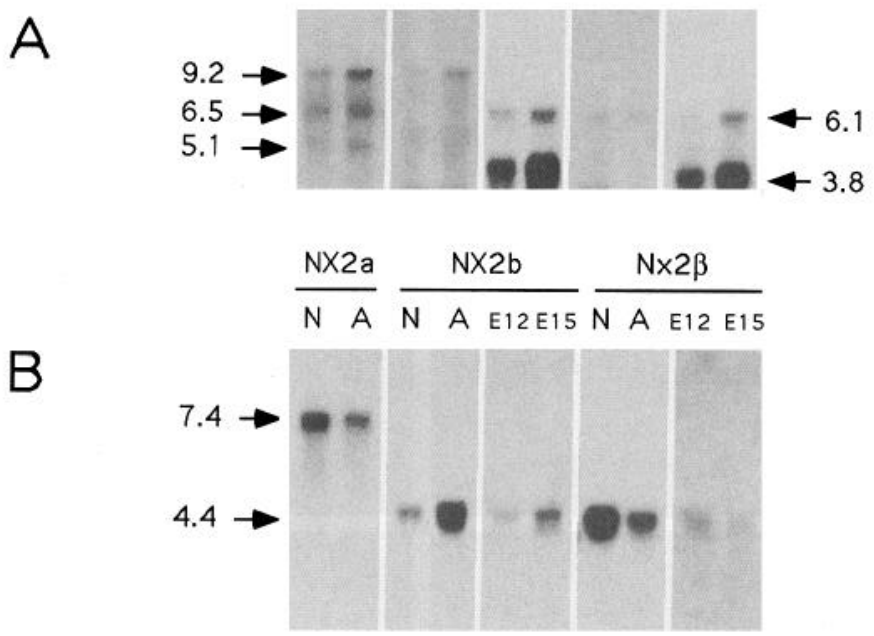

Figure 2. Northern blot analysis of neurexin expression. $A$, PolyA $^{+}$ RNA ( $2 \mu \mathrm{g}$ per lane) from E12 (lanes E12) or E15 (lane E15) embryos, and from newborn (lanes $N$ ) or adult (lanes $A$ ) brain was separated on formaldehyde gels, blotted onto a nylon membrane and hybridized with the NX1, NX1a, NX1b, or NX1 $\beta$ probes as indicated. $B$, As $A$, but polyA ${ }^{+}$mRNA was hybridized with the NX2a, NX2b, or NX2 $\beta$ probes as indicated. All hybridizations were done with blots run in parallel or probed consecutively. All blots were hybridized with a $\gamma$-actin probe to show that similar amounts of mRNA were loaded (data not shown). In $A$, lanes $3,4,7$, and 8 (bottom), a residual signal from a previous actin hybridization is visible. Transcript sizes are indicated in kilobases.

$65^{\circ} \mathrm{C}$ in $2 \times \mathrm{SSC}, 0.1 \%(\mathrm{w} / \mathrm{v}) \mathrm{SDS}$, and twice at $65^{\circ} \mathrm{C}$ in $0.1 \times \mathrm{SSC}$, $0.1 \%(\mathrm{w} / \mathrm{v})$ SDS. After exposition hybridized probes were removed from blots by incubation in $90 \%(\mathrm{v} / \mathrm{v})$ formamide, $10 \mathrm{~mm}$ EDTA, 10 $\mathrm{mM}$ Tris/ $\mathrm{HCl}(\mathrm{pH} 8.0)$ at $60^{\circ} \mathrm{C}$ for $30 \mathrm{~min}$ and rehybridized up to five times.

In situ hybridization. In situ hybridization of paraffin sections was done as described previously using ${ }^{35} \mathrm{~S}$-labeled RNA probes (Püschel et al., 1992). Only signals detected in several independent experiments and on several sections were considered for the description of transcript expression patterns.

\section{Results}

\section{Northern blot analysis of neurexin transcripts}

In order to analyze the expression patterns of the major isoforms of the three neurexin genes during murine embryonic development, several specific probes were generated by PCR. Based on the published rat sequences primers were designed to amplify the corresponding sequences from murine cDNA generated from E12 embryonic or adult brain mRNA (Table 1, Fig. 1; see also Materials and Methods). To avoid cross-hybridization of the probes, primer sequences were chosen from untranslated sequences whenever possible. We first analyzed neurexin expression by Northern blot hybridization to confirm the specificity of the probes and for an initial characterization of the expression profiles of the neurexin genes (Fig. 2).

A $1.9 \mathrm{~kb}$ BamHI fragment from the rat neurexin I cDNA (probe NX1) detected three transcripts of $9.2 \mathrm{~kb}, 6.5 \mathrm{~kb}$, and 5.1 $\mathrm{kb}$ of similar abundance in both newborn and adult mouse brain (Fig. 2A). The $9.2 \mathrm{~kb}$ transcript was also detected by the NX1a probe (Fig. $2 A$ ) and corresponds in size to the rat neurexin I $\alpha$ transcript (Ushkaryov et al., 1992). A $6.1 \mathrm{~kb}$ mRNA was seen when using probes NX1b and NX1 $\beta$ (Fig. $2 A$ ) and is similar in size to the rat neurexin I $\beta$ mRNA (Ushkaryov et al., 1992). In addition, a strong signal at $3.8 \mathrm{~kb}$ was observed with the NX1b probe both in E12 and E15 embryos and in newborn and adult brain (Fig. 2A). This transcript was of much higher abundance than the $6.1 \mathrm{~kb}$ neurexin I $\beta$ RNA. NX1b did not hybridize to the neurexin $\mathrm{I} \alpha$ transcript in Northern blot analysis as was expected from the published neurexin I sequence. Also, this probe gave a different pattern from that of the NXla probe when used for in situ hybridization experiments (see below).

Probe NX2a hybridized to a single transcript of $7.4 \mathrm{~kb}$ (Fig. $2 B$ ) which is in good agreement with the reported size of the rat neurexin II $\alpha$ transcript (Ushkaryov et al., 1992). A transcript of the same size as the rat neurexin II $\beta$ RNA $(4.4 \mathrm{~kb})$ was seen with both the NX2b and NX2 $\beta$ probes in embryos and newborn and adult brain (Fig. $2 B$ ), with levels increasing from E12 to adult stages. The NX3a probe hybridized to a $8 \mathrm{~kb}$ transcript in newborn and adult brain which is in accordance with results obtained with rat brain (not shown). However, no signals were detected when using either the NX3Sa or NX3Sb probes (data not shown).

\section{In situ hybridization analysis of neurexin expression during embryonic development}

The spatial and temporal expression patterns of the three neurexin genes were examined using antisense RNA probes derived from the cloned fragments NX1a, NX1b, NX1 $1 \beta, N X 2 a, N X 2 b$, $\mathrm{NX} 2 \beta, \mathrm{NX} 3 \mathrm{a}$, and NX3Sb. The NX1b and NX1 $\beta$, as well as the NX2b and NX2 $\beta$, probes gave identical results both on Northern blots (see above) and in situ hybridization experiments (data not shown), and they detected the neurexin $\mathrm{I} \beta$ and neurexin II $\beta$ transcripts, respectively. We used the NX1b and NX2b probes for all further analysis. No specific hybridization was obtained with NX3Sb (data not shown).

\section{Expression in spinal cord and PNS}

At E12 all neurexin genes were expressed in the developing nervous system exclusively in postmitotic neurons (Fig. 3). In the thoracic spinal cord the probes NX1a, NX1b, NX2a, and NX2b gave similar results. In dorsal root ganglia (DRG), however, NX1b detected low, and NX2a no signals above background (Fig. 3G,H). Probe NX3a revealed a more restricted transcript pattern with strong hybridization in the more medial part of the mantle zone, whereas the intermediate zone and the most ventral part of the spinal cord were not labeled (Fig. $3 J$ ). Expression of all three neurexin genes was more restricted at the lumbar level (Fig. $3 A-E$ ). As already seen in the thoracic region, NX1a and NX1b showed hybridization patterns very similar to that produced by the NX2a and NX2b probes. This expression domain showed little or no overlap with that detected by NX3a. Thus, neurexins I/II and neurexin III may initially be expressed in mutually exclusive cell populations. As judged by their respective positions in the mantle zone, transcripts of all three genes accumulated within a day after the neurons became postmitotic (Nornes and Carry, 1978; Altman and Bayer, 1984). These findings were corroborated by Northern blot analysis (data not shown) and by in situ hybridization with the NX1b, NX2b and NX3a probes of thoracic cross sections obtained from E10 and E11 embryos (data not shown). These gave similar results as obtained for the caudal region of E12 embryos.

At E15 the majority of the neurons have been born in the spinal cord (Nornes and Carry, 1978; Altman and Bayer, 1984). At this stage the expression patterns of the different neurexin genes became more distinct. $\mathrm{NX} 1 \mathrm{a} / \mathrm{b}$ hybridization signals were 

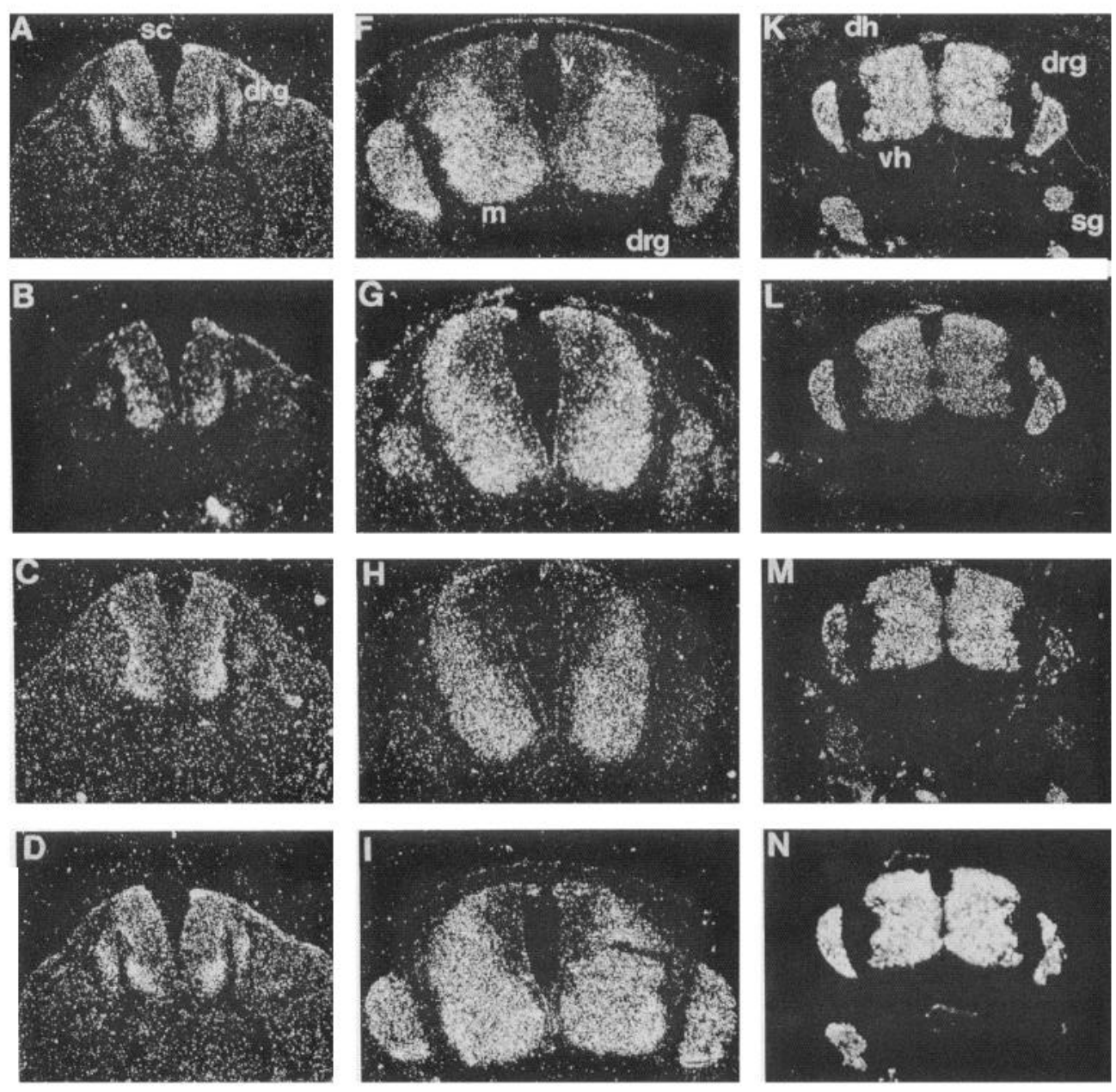

Figure 3. Cross sections of E12 (Afrom the lumbar $(A-E)$ or thoracic level $(F-O)$ were hybridized with the NX1a $(A, F, K), \mathrm{NX} 1 \mathrm{~b}(B, G, L), \mathrm{NX} 2 \mathrm{a}(C$, $H, M), \mathrm{NX} 2 \mathrm{~b}(D, I, N)$, or NX3a $(E, J$, $O$ ) probes. Expression is seen in spinal cord $(s c)$, dorsal root ganglia $(\mathrm{drg})$, and sympathetic ganglia $(s g)$. $d h$, Dorsal horn; $v h$, ventral horn; $v$, ventricular layer; $m$, mantle layer. Scale bar: $A-H$, $200 \mu \mathrm{m} ; K-O, 400 \mu \mathrm{m}$.
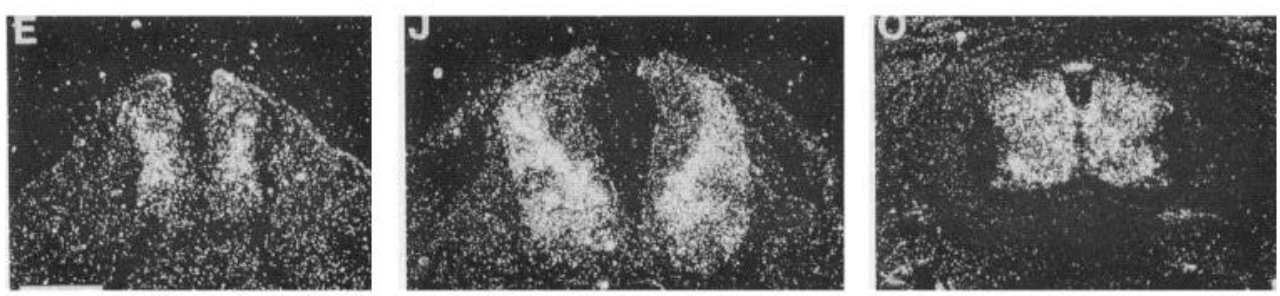

found throughout the gray matter of the spinal cord with somewhat higher levels in the dorsal horn, whereas NX2a/b showed very strong and uniform expression (Fig. $3 K-N$ ). The NX3a probe labeled a subset of neurons that are uniformly scattered throughout the spinal cord (Fig. 3O). Significant differences in transcript distribution were obvious in DRGs and sympathetic ganglia (SG) at this stage (Fig. 4). All isoforms of the neurexin I and II mRNAs were present in DRGs (Fig. $4 A-H$ ) whereas only neurexin I $\alpha$ and II $\beta$ transcripts were detected in SGs (Fig. $4 A, G)$. The neurexin III gene was not expressed in any of these structures (Fig. 3O). Only a subset of DRG neurons showed a signal with the NX2a probe (Fig. $4 F$ ).

\section{Expression in embryonic brain}

At E12 the neurexin I and II genes showed very similar expression patterns in the developing brain. Both the $\alpha$ - and $\beta$ isoforms were detected in all parts of the brain with the exception of the forebrain, where only weak signals were seen (Fig. $5 A-D)$. Hybridization was restricted to postmitotic neurons which had already left the ventricular zone. Similar to the data obtained for spinal cord, NX3a detected a more restricted expression pattern (Fig. $5 E$ ). No expression was seen in the roof of the midbrain (tectum) but high levels were obvious in the tegmentum and at the midbrain/forebrain junction (Fig. 5E). Neurexin III mRNA was strongly expressed in the prospective basal forebrain (ganglionic eminence) at higher levels compared to those of neurexin I and II transcripts. All neurexin mRNAs were absent from the frontal cortex at this stage.

At E15 most brain regions as well as the cervical ganglia expressed neurexin $\mathrm{I} \alpha, \mathrm{II} \alpha, \mathrm{I} \beta$, and II $\beta$ mRNAs in a very similar pattern (Fig. $5 F-I$ ). Whereas the trigeminal ganglion contained all forms of neurexin I and II transcripts, the superior cervical ganglion expressed only neurexins I $\alpha$ and II $\beta$ (Figs. $5 F-J, 6 A-$ $D$ ). Strong hybridization signals were seen throughout the hindand midbrain including the cerebellar primordium. The anterior parts of the tectum displayed higher levels of neurexin transcripts than its more posterior parts. In the frontal cortex strong signals were observed in the cortical plate, part of the striatum, 

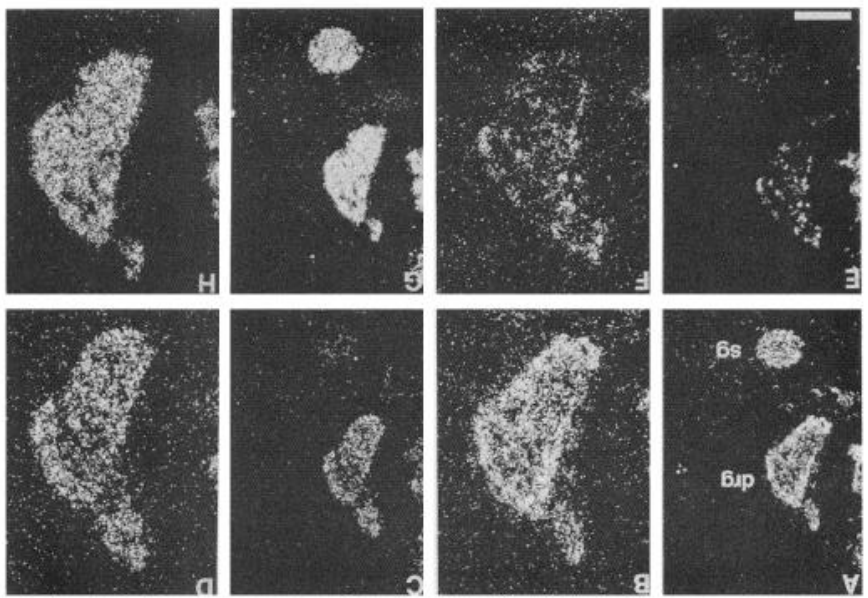

Figure 4. Cross sections of E15 mouse embryos from the thoracic level were hybridized with the NX1a $(A, B)$, NX1b $(C, D), \mathrm{NX} 2 \mathrm{a}(E$, $F)$, or NX2b $(G, H)$ probes. Expression is seen in the dorsal root $(\mathrm{drg})$ in $A, C, E$, and $G$ and sympathetic ganglia $(s g)$ in $A$ and $G$. A higher magnification of the DRGs displayed in $A, C, E$, and $G$ is shown in $B$, $D, F, H$. Note that only a subset of DRG neurons express neurexin II $\alpha$. Medial is to the left. Scale bar: $A, C, E, G, 200 \mu \mathrm{m} ; B, D, F, H, 100$ $\mu \mathrm{m}$.

and the hippocampus (Fig. $5 K-N$ ). The neurexin III probe showed a different pattern with prominent expression in the striatum (the caudate-putamen; Fig. $5 J$ ) and some restricted cell populations in the cortex and mid- and hindbrain. In the frontal cortex two distinct cell layers in the cortical plate and at the interface between the cortical neuroepithelium and the corpus callosum showed neurexin III signals (Fig. 5O). Neurexin III was absent or only weakly expressed in cervical ganglia. The olfactory epithelium (Fig. $7 C$, and data not shown) and the retina contained all neurexin mRNAs at E15 (Fig. 7A,B, data not shown). Neurexin I and II transcripts were found in all cells of the inner nuclear layer of the retina, whereas neurexin III mRNA was restricted to a small zone of the inner nuclear layer adjacent to the outer nuclear layer. Outside the CNS, the neurexin III gene was activated around the primordia of the vibrissa follicles (Fig. 7D).

\section{Discussion}

The neurexins form a small gene family of three highly related genes that give rise to a great variety of alternatively spliced transcripts (Ushkaryov et al., 1992). These genes are almost exclusively expressed in neural tissue (with the notable exception of neurexin III; see above), and the neurexin I protein is highly enriched at synapses (Valtorta et al., 1984; Ushkaryov et al., 1992). Originally the neurexins were isolated as components of the purified receptor for a toxin from black widow spider venom, $\alpha$-latrotoxin (Ushkaryov et al., 1992; Petrenko et al., 1993). This toxin binds to a receptor on synaptic terminals and induces a massive $\mathrm{Ca}^{2+}$ independent release of neurotransmitter (Frontali et al., 1976; Nicholls et al., 1982; Deri et al., 1993). Notably, in vitro the C-terminal tail region of neurexin binds to synaptotagmin (Petrenko et al., 1991; Hata et al., 1993; O'Connor et al., 1994), a synaptic vesicle membrane protein implicated in the $\mathrm{Ca}^{2+}$ triggering of synaptic vesicle exocytosis (Bommert et al., 1993; DeBello et al., 1993; Elferink et al., 1993).

Northern blot hybridizations revealed a complex pattern of neurexin transcripts in mouse embryos and brain. In addition to the known major $\alpha$ - and $\beta$-isoforms we found a smaller transcript of $3.8 \mathrm{~kb}$ which was detected only by the NX1b probe. We consider it unlikely that this result reflects cross-hybridization to related gene products because of the high stringency of the hybridization procedure used. Thus, the $3.8 \mathrm{~kb}$ transcript, which is the most abundant neurexin I mRNA found in this study, may represent another alternatively spliced variant or the product of an alternative polyA addition site. This interpretation is supported by our in situ hybridization analysis which gave identical results with the NX1b and NX1 $\beta$ probes. In contrast, the NX1b probe did not hybridize to the neurexin $\mathrm{I} \alpha$ transcript, a result that is difficult to reconcile with the data published by Ushkaryov et al. (1992). As these authors did not specify the probes used in their Northern blot analysis, we have no explanation for our failure to detect the neurexin $\mathrm{I} \alpha$ mRNA with the NX1b probe.

The neurexin genes are expressed as early as E10 in the embryonic nervous system of the mouse. In situ hybridization showed that their expression is limited to postmitotic neurons and increases with development as more neurons are born. During the development of the embryonic nervous system mitotic neuronal precursors are located in the ventricular zone (Nornes and Carry, 1978; Altman and Bayer, 1984). After completion of their final mitosis the cells migrate from the ventricular zone to the mantle zone where their terminal differentiation takes place. In the spinal cord the extent of the mantle zone increases by the continuous addition of new postmitotic neurons between E9 and E15. As a general rule this process proceeds from anterior to posterior and ventral to dorsal with the more anteriorly and ventrally located neurons being the more mature cells of the developing spinal cord. Accordingly, expression of all three neurexin genes is more restricted at the lumbar, more immature, level where the development of neurons lags by approximately $1 \mathrm{~d}$ relative to the thoracic region. Neurexins $\mathrm{I} \alpha, \mathrm{II} \alpha, \mathrm{I} \beta$, and $\mathrm{II} \beta$ show very similar expression patterns in the CNS. In spinal cord neurexin I $\alpha$ and I $\beta$ transcripts are expressed at a slightly higher level in the dorsal horn as compared to the other layers, whereas neurexin II $\alpha$ and II $\beta$ mRNAs are expressed uniformly throughout the gray matter. Neurexin III differs from the other genes by its more restricted expression pattern. Major differences in expression are seen in the PNS (Table 2). All isoforms of the neurexin I and II mRNAs were present in DRGs whereas only neurexin I $\alpha$ and II $\beta$ signals were detected in SGs. The same observation was made in the cranial region. Whereas all neurexin I and II transcripts were found in the trigeminal ganglion, only neurexin I $\alpha$ and II $\beta$ expression was detected in the superior cervical ganglion. The neurexin III gene was not expressed in any of these structures. All neurexin transcripts were found in the spinal cord as early as E10, that is, at least $1 \mathrm{~d}$ before synapses are formed. However, neurexin mRNAs are present only in structures where synapses are formed or which are innervated: the CNS and PNS, the retina, the whisker pads and the olfactory epithelium. The differences in peripheral expression patterns as well as the more restricted transcription of neurexin III indicate that each neurexin might have a specific role in the different structures.

Our results may reflect the possibility that the neurexin genes are active long before synapses are formed, whereas the encoded proteins are required only later for synaptic transmission. However, although it is dangerous to draw conclusions from transcript distributions without information about the expression of the corresponding proteins, we think that our data allow some 

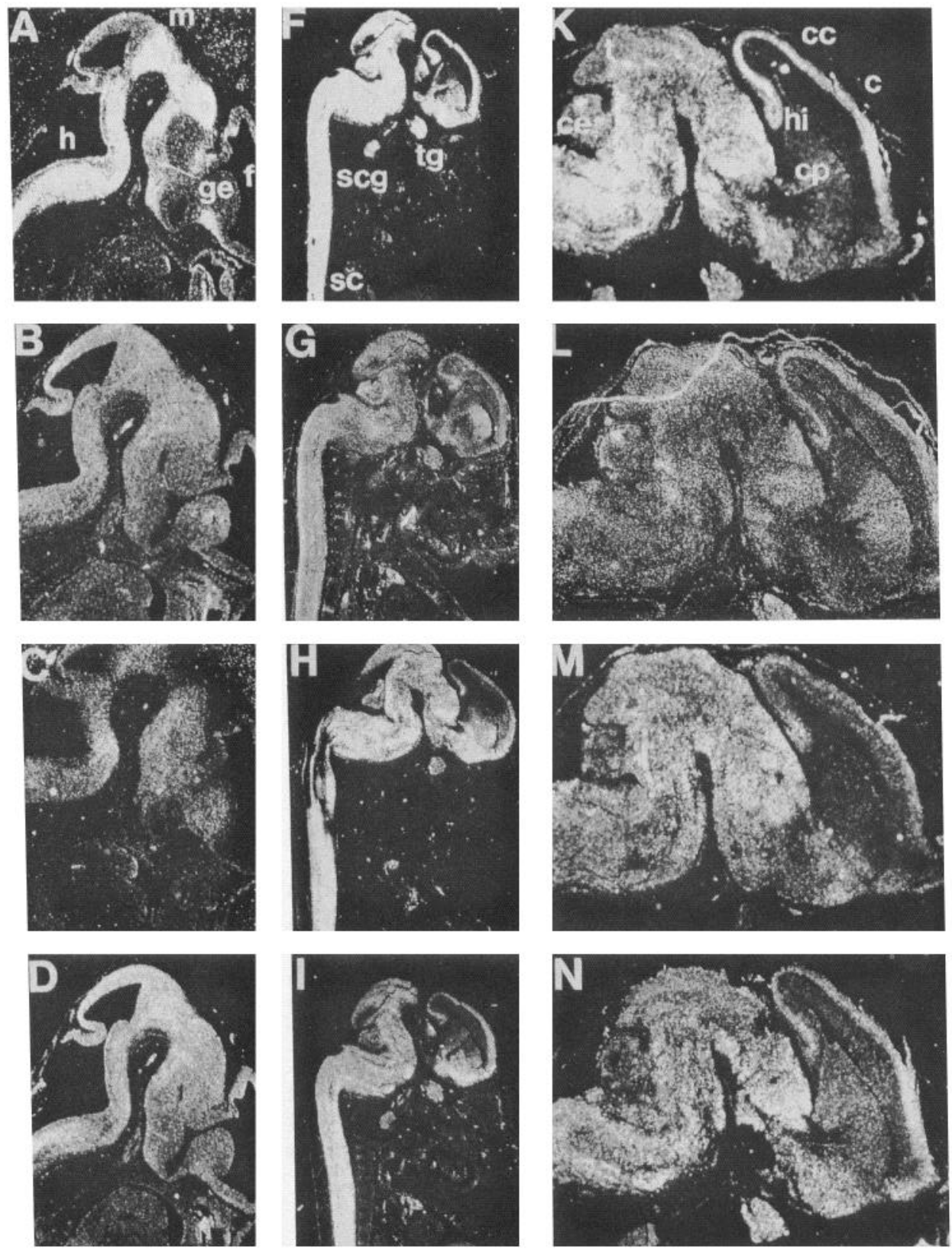

Figure 5. Sagittal sections of E12 (A$E)$ and E15 $(F-O)$ mouse embryos were hybridized with the NX1a $(A, F$ $K)$, NX1b $(B, G, L)$, NX2a $(C, H, M)$, $\mathrm{NX} 2 \mathrm{~b}(D, I, N)$, or NX3a $(E, J, O)$ probes. Expression was seen in the hindbrain $(h)$, midbrain $(m)$, cerebellar primordium $(c e)$, forebrain $(f)$ including the caudate-putamen $(c p)$, the cortical plate $(c)$, the hippocampus (hi), the tectum $(t)$, the trigeminal ganglion $(\mathrm{tg})$, the superior cervical ganglion $(s c g)$, and the spinal cord $(s c) . K-O$, Neurexins are differentially expressed in E15 brain. $c c$, Corpus callosum. $g e$, Ganglionic eminence. Scale bar: $A-E$ and $K-O, 800 \mu \mathrm{m} ; F-J, 1600 \mu \mathrm{m}$.
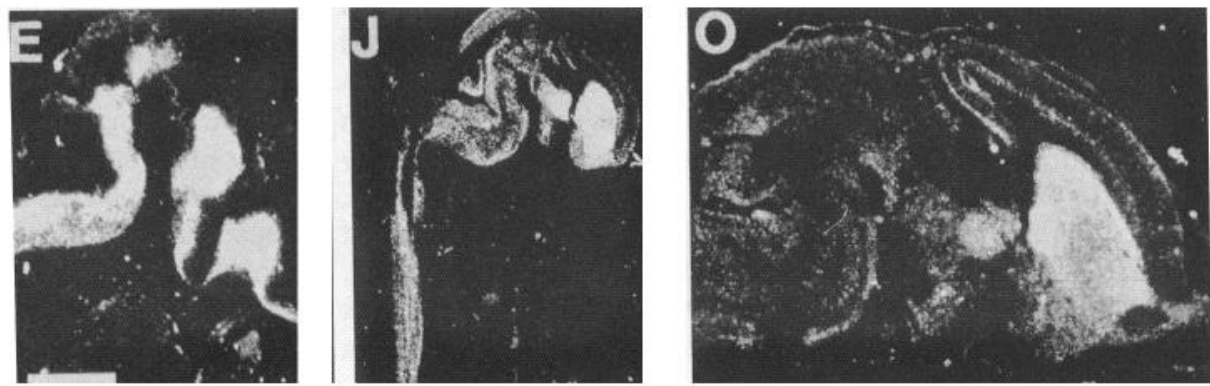

further suggestions on the possible function of neurexins. Two different but not mutually exclusive hypotheses for a function of neurexins have been put forward. Neurexin I was shown to interact with some proteins of a multicomponent complex (the $20 \mathrm{~S}$ complex) implicated in the regulated vesicular release of neurotransmitters at central synapses, and therefore may be a component of the release apparatus (O'Connor et al., 1993; Hata et al., 1993). Alternatively, the neurexins have been suggested to act as synaptic cell recognition molecules that mediate cellcell or cell-matrix interactions (Ushkaryov et al., 1992).

As expression of neurexin transcripts precedes synaptogenesis it is likely that their suggested involvement in the vesicular release of neurotransmitters is not their sole function. Similar to the neurexins, transcripts for several proteins of the $20 \mathrm{~S}$ fusion 

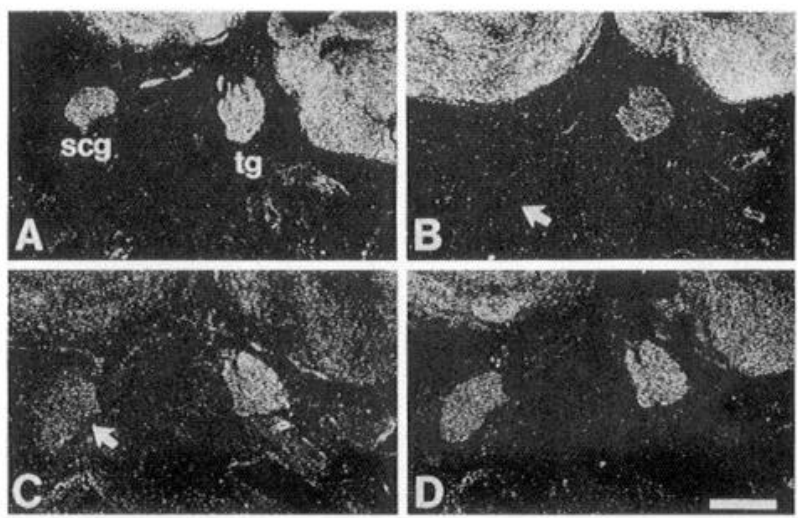

Figure 6. Sagittal sections of E15 mouse embryos were hybridized with the NX1a $(A), \mathrm{NX} 1 \mathrm{~b}(B), \mathrm{NX} 2 \mathrm{a}(C)$, and NX2b $(D)$ probes. Expression is seen in the trigeminal ganglion $(t g)$, and the superior cervical ganglion $(\mathrm{scg})$. Arrows indicate positions of superior cervical ganglia which do not express neurexin $\mathrm{I} \beta(B)$ or II $\alpha(C)$ transcripts. Scale bar, $550 \mu \mathrm{m}$.

complex (i.e., NSF, $\alpha / \beta$-SNAP) mediating the docking and fusion of vesicles with different membranes (Bennett and Scheller, 1993; Söllner et al., 1993; Bennett and Scheller, 1994) are detected before synapses are formed (Püschel et al., 1994). Interestingly, synaptotagmin, which interacts with neurexin I in vitro, stimulates filopodia formation upon transfection into fibroblasts (Feany and Buckley, 1993). The presynaptic membrane protein SNAP-25, another component of the 20 S fusion complex, has been shown to be necessary for the growth of developing axons (Osen-Sand et al., 1993). Thus, similar to SNAP-25, the neurexins might also be involved in axogenesis. This would suggest that neurotransmitter release and axogenesis are based on similar mechanisms. A role of neurexins in axon growth may account for their early embryonic expression. However, other possible functions, for example, cell-cell or cell-extracellular matrix interactions are equally conceivable. Localized interactions with
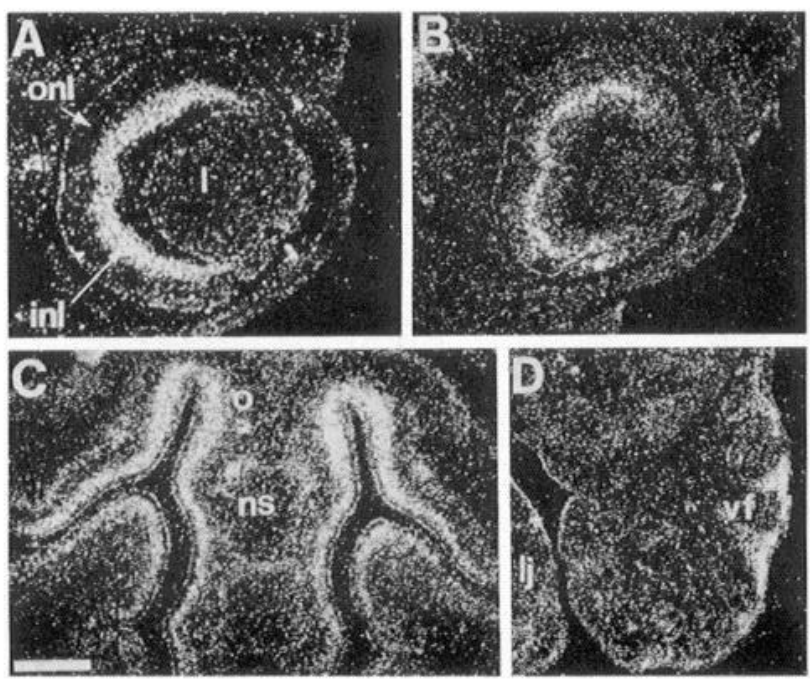

Figure 7. Cross sections $(A-C)$ and a sagittal section $(D)$ of E15 mouse embryos were hybridized with the NXla $(A, C)$ or NX3a probes $(B, D)$. Expression is seen $(A, B)$ in the developing retina in the inner nuclear layer (inl), but not in the outer nuclear layer $(o n l),(C)$ in the olfactory epithelium $(o),(D)$ near the primordia of the vibrissa follicles $(v f)$ of the snout. $n s$, Nasal septum; $l$, lens; $l j$, lower jaw. Scale bar: $A$ and $B, 100 \mu \mathrm{m} ; C, 400 \mu \mathrm{m} ; D, 800 \mu \mathrm{m}$.
Table 2. Neurexin expression in the embryonic central and peripheral nervous system at $\mathbf{E} 15$

\begin{tabular}{lllllll} 
Transcript & SC & DRG & SG & TG & SCG & Brain \\
\hline Neurexin I $\alpha$ & + & + & + & + & + & + \\
Neurexin I $\beta$ & + & + & - & + & - & + \\
Neurexin II $\alpha$ & + & $*$ & - & + & - & + \\
Neurexin II $\beta$ & + & + & + & + & + & + \\
Neurexin III $\alpha$ & $*$ & - & - & - & - & +
\end{tabular}

Data are summarized from in situ hybridizations as shown in Figures 3-6. +, expression in all or most cells; *, expression in subset of cells; - , no expression. SC, spinal cord; DRG, dorsal root ganglia; SG, sympathetic ganglia; TG, trigeminal ganglion; SCG, superior cervical ganglion.

the extracellular environment could even help to organize the assembly of active zones at differentiating synapses, thus coupling extracellular signals to a localized docking and fusion of synaptic vesicles. Our analysis of the neurexin expression pattern constitutes only a first step towards further elucidating the function of these neuronal membrane components.

\section{References}

Altman J, Bayer SA (1984) The development of the rat spinal cord. In: Advances in anatomy and cell biology, Vol 85, Berlin: Springer. Bennett MK, Scheller RH (1993) The molecular machinery for secretion is conserved from yeast to neurons. Proc Natl Acad Sci USA 90:2559-2563.

Bennett MK, Scheller RH (1994) Molecular correlates of synaptic vesicle docking and fusion. Curr Opin Neurobiol 4:324-329.

Bommert K, Charlton MP, DeBello WM, Chin GJ, Betz H, Augustine GJ (1993) Inhibition of neurotransmitter release by C2-domain peptides implicates synaptotagmin in exocytosis. Nature 363:163-165.

DeBello WM, Betz H, Augustine GJ (1993) Synaptotagmin and neurotransmitter release. Cell 74:947-950.

Deri Z, Bors P, Adam-Vizi V (1993) Effect of $\alpha$-latrotoxin on acetylcholine release and intracellular $\mathrm{Ca}^{2+}$ concentration in synaptosomes: $\mathrm{Na}^{+}$-dependent and $\mathrm{Na}^{+}$-independent components. J Neurochem 60 : 1065-1072.

Elferink LA, Peterson MR, Scheller RH (1993) A role for synaptotagmin (p65) in regulated exocytosis. Cell 72:153-159.

Feany MB, Buckley KM (1993) The synaptic vesicle protein synaptotagmin promotes formation of filopodia in fibroblasts. Nature 364 : 537-540.

Frontali N, Ceccarelli B, Gorio A, Mauro A, Siekvitz P, Tzeng MC, Hurlbut WP (1976) Purification from black widow spider venom of a protein factor causing the depletion of synaptic vesicles at neuromuscular junctions. J Cell Biol 68:462-479.

Hata Y, Davletov B, Petrenko AG, Jahn R, Sudhof TC (1993) Interaction of synaptotagmin with the cytoplasmic domains of neurexins. Neuron 10:307-315.

Meldolesi J (1982) Studies on $\alpha$-latrotoxin receptors in rat brain synaptosomes: correlation between toxin binding and stimulation of transmitter release. J Neurochem 38:1559-1569.

Nicholls DG, Rugolo M, Scott IG, Meldolesi J (1982) $\alpha$-Latrotoxin of black widow spider venom depolarizes the plasma membrane, induces massive calcium influx, and stimulates transmitter release in guinea pig brain synaptosomes. Proc Natl Acad Sci USA 79:7924-7928.

Nornes HO, Carry M (1978) Neurogenesis in spinal cord of mouse: an autoradiographic analysis. Brain Res 159:1-16.

O'Connor V, Augustine GJ, Betz H (1994) Synaptic vesicle exocytosis: molecules and models. Cell 76:785-787.

O'Connor VM, Shamotienko O, Grishin E, Betz H (1993) On the structure of the 'synaptosecretosome'. Evidence for a neurexin/synaptotagmin/syntaxin/ $\mathrm{Ca}^{2+}$ channel complex. FEBS Lett 326:255-260.

Osen-Sand A, Catsicas M, Staple JK, Jones KA, Ayala G, Knowles J, Grenningloh G, Catsicas S (1993) Inhibition of axonal growth by SNAP-25 antisense oligonucleotides in vitro and in vivo. Nature 364 : 445-448.

Perin MS (1994) The $\mathrm{COOH}$ terminus of synaptotagmin mediates interaction with the neurexins. J Biol Chem 269:8576-8581. 
Petrenko AG (1993) $\alpha$-Latrotoxin receptor. Implications in nerve terminal function. FEBS Lett 325:81-85.

Petrenko AG, Perin MS, Davletov BA, Ushkaryov YA, Geppert M, Südhof T (1991) Binding of synaptotagmin to the $\alpha$-latrotoxin receptor implicates both in synaptic vesicle exocytosis. Nature 65-68.

Petrenko AG, Lazaryeva VD, Geppert M, Tarasyuk TA, Moomaw C, Khokhlatchev AV, Ushkaryov YA, Slaughter C, Nasimov IV, Sudhof TC (1993) Polypeptide composition of the $\alpha$-latrotoxin high molecular weight polypeptides complexed to a low molecular weight protein. J Biol Chem 268:1860-1867.

Püschel AW, Balling R, Gruss P (1990) Position-specific activity of the Hox 1.1-promoter in transgenic mice. Development 108:435-442.

Püschel AW, Gruss P, Westerfield M (1992) Sequence and expression pattern of pax- 6 are highly conserved between zebrafish and mice. Development 114:643-651.
Püschel AW, O'Connor VM, Betz H (1994) The $N$-ethylmaleimidesensitive fusion protein (NSF) is preferentially expressed in the nervous system. FEBS Lett 347:55-58.

Söllner T, Whiteheart SW, Brunner M, Frdjument-Bromage H, Geromanos S, Tempst P, Rothman JE (1993) SNAP receptors implicated in vesicle targeting and fusion. Nature 363:318-324.

Ushkaryov YA, Südhof TC (1993) Neurexin III $\alpha$ : extensive alternative splicing generates membrane-bound and soluble forms. Proc Natl Acad Sci USA 90:6410-6414.

Ushkaryov YA, Petrenko AG, Geppert M, Südhof TC (1992) Neurexins: synaptic cell surface proteins related to the $\alpha$-latrotoxin receptor and laminin. Science 257:50-56.

Valtorta F, Madeddu L, Meldolesi J, Ceccarelli B (1984) Specific localization of the $\alpha$-latrotoxin receptor in the nerve terminal plasma membrane. J Cell Biol 99:124-132. 